\title{
Risky Transitions. Vocational Development between Traumatic Biography and the Search for Identity
}

\author{
Julian Valentin Möhring, Dennis Schäfer, Burkhard Brosig \\ Faculty of Medicine, Department for Child and Family Psychosomatics at the Clinic for General Pediatrics and Neonatology of the \\ University Clinic, Giessen, Germany \\ Email: julian.moehring@sowi.uni-giessen.de
}

How to cite this paper: Möhring, J. V., Schäfer, D., \& Brosig, B. (2021). Risky Transitions. Vocational Development between Traumatic Biography and the Search for Identity. Advances in Applied Sociology, 11, 669-694.

https://doi.org/10.4236/aasoci.2021.1112056

Received: November 8, 2021

Accepted: December 25, 2021

Published: December 28, 2021

Copyright $\odot 2021$ by author(s) and Scientific Research Publishing Inc. This work is licensed under the Creative Commons Attribution International License (CC BY 4.0).

http://creativecommons.org/licenses/by/4.0/ (c) (i) Open Access

\begin{abstract}
The article provides insights into the interaction between different stages of identity formation in emerging adults with complex constellations of biographical problems. They went through a program for professional qualification with optional psycho-social counseling following completion of their compulsory schooling. A very specific individuation is demanded of the subject in the transition from youth to adulthood. Biographical interviews were conducted with a total of 10 participants aged 20 to 27 years, and 3 interviews were presented in detail as case studies. They were finally evaluated in terms of in-depth hermeneutics with the aim of understanding the latent meaning of biographical transitions in the light of identity development. Based on the presentation of psychoanalytic development concepts of identity and, above all, Arnett's theory of emerging adulthood, the interviews are hermeneutically reconstructed and theoretically contextualized. The biographic narratives are understood as expressions of the bio-psycho-social processes of identity-formation as well as the body-bound, habitual and emotional parts of biography. The analysis reveals both the dynamics of progression and regression in career orientation and the risks that may come with the creation of meaningful transitions. It becomes clear that even under conditions of the neglect and traumatization, of parentification and functionalization, emerging adults can fight for freedom and independence.
\end{abstract}

\section{Keywords}

Emerging Adulthood, Identity, Habitus, Precarious Career Choice, Psychoanalytic Social Case Work

\section{Risks to Identity Formation during the Transition Phase}

"Me and the machines: I love the machines, I love sliding table saws."1 
At the transition from school to working life, the internal concepts of self are breached by social activities. Mastering the risky transitions between school and working life can be understood as a question of experiencing continuity during the identify formation process amidst both external as well as internal struggles. As a question of authenticity, it points both to the demands society puts on emerging adults as well as the subjective meaningful dimension of experience and plans for the future. Particularly in a transitional system, the mastering of risky transitions is difficult to grasp as a subjective fulfilling of functions, such as the attainment of maturity to enter vocational training and the corresponding competencies. Following Vera King $(2013,2020)$, this process can be more precisely formulated with the concept of generativity, as a "societal regulation of emulation and new start" (King, 2020: p. 361), formulated as a simultaneous change in the family realm and the occupational realm during the transition into adulthood. The interaction of the innovative impulses of emerging adults with the leeway (breathing space) that they are granted by the elder generation takes place in a tension-filled process of a mutual and reciprocal sounding out of future opportunities. Emerging adults' lines of conflict run along generational boundaries, although they also run along other social boundaries.

\section{Finding New Angles on Risky Transitions}

The perspective that emerging adults take on their own life situation still isn't understood well, at least for those having trouble at the transition from school to work (Hirschfeld, 2020: p. 13f.). Their failure in taking up an ordinary occupation is often enough conceived in a deficient and attributive way. Discussing emerging adults' strategies to cope with not having an apprenticeship, how they can be informed, supported and activated to be successful in their transition reproduces narratives of failure. Emerging adults are held accountable for their own life situation if it is seen at most as their responsibility to find a suitable way into working life. In our biographical interviews we aim at a strongly involved perspective to get new insights on what taking part in a vocational measure means in terms of personal development as an emerging adult.

With the opening citation, the trainee carpenter Carla $^{1}$ describes what is driving her on the path to her vocational identity. This quote is from an interview conducted in concomitant research at a psycho-social counseling office on the premises of a training institute. Narrative interviews were conducted with a total of ten persons. The in-depth hermeneutic evaluation of the interview with Carla, an apprentice who earlier made up for her secondary school diploma in a qualification measure, illustrates how a young woman libidinously charges her work in a wood workshop. Under observation is the role a vocational qualification measure plays in the identity formation of people who also have unsettled training prospects, finding themselves in psychologically problematic situations.

${ }^{1}$ Personal information has been anonymized; see section 2 in this article. 
Vocational qualification measures are intended to assist those people with the transition to the workforce who, following completion of their secondary schooling, were not able to obtain an apprenticeship or acceptance by an institute of higher learning. Many of them are dependent on social welfare by way of unemployment benefits [Arbeitslosengeld-II (ALG-II]. Vocational choice qualification crises in this setting usually last from several months to years (Beicht \& Eberhard, 2013). Successful transitions require educational success (above all, the secondary school diploma) and basic competences (e.g. reliability and ability to cope under pressure). They are also tied to institutional rhythms, namely the start of the training year. The typical focus of transition measures on career identification and choice alone is not adequate as an answer to the development crisis of young people in the transition system. This (sham-) offer frequently breaks apart under the weight of their troubled biography (see Förster-Chanda, 2020: p. 139). For emerging adults, a qualification crisis is frequently accompanied by psychological stress, which neither the social system nor the health care system satisfactorily addresses. Consequently, there is a risk the problems of identity development in vocational qualification measures will not be intercepted. It often well exceeds the pedagogical aims of participation in such a measure and endangers the vocational development. The two intermediate objectives of transitional offerings, stabilization and qualification, are designed to improve the starting position in the competition for training opportunities and the transition to a regular training situation; they easily overwhelm these people when the foundation for serious work towards these goals has not been laid down in their day-to-day life. Moreover, the mechanisms of marginalization intensify during weak economic phases and those who are weaker fall by the wayside. As Carla also reports, there are additional hurdles such as acquired skills that can often not be credited towards the training period (e.g. how to operate machinery). Even the low-threshold practical learning approach for vocational orientation in (repair or construction) workshops can prove futile if it is not embedded in a holistic concept for personal development.

In a concept to create a hinge between social welfare and psychosomatic care, using the premises of a voluntary social welfare agency, a pilot project for on-site psycho-social counseling was set up and evaluated by way of accompanying research (Förster-Chanda, 2020; Förster-Chanda et al., 2013; Schäfer et al., 2020). The counseling work is psycho-dynamic and focal therapeutical in nature and is targeted towards current personal crises. It establishes transitions in out-patient and in-patient therapies and stabilizes personal developments in the qualification measure. In this psychoanalytically-shaped social work project, hurdles with socially disadvantaged emerging adults are reduced in order to promote the acceptance of therapeutic measures. The on-site psycho-social counseling also serves as support to overcome acute qualification crises. In this setting, psycho-social counseling (Schnoor, 2011) is tasked with bringing back clients who are out of line with the pedagogic qualification offerings. During crisis management, counselors are not limited in their counseling to only short-term im- 
provements in individual coping skills to promote a client's professional development and ensure success in the qualification measure. They also advance their clients reflectivity. The commitment to a concrete professional developmental goal is often only obtainable when the activity can be seen in a broader biographical context. Hereby, the circumstances are emphasized during the process of counseling that the causes of one's own difficulties are not only to be found within the person, but rather that social factors also make a major contribution. The social embedding of clients in families and other social structures is assigned particular significance with the broader-approach root-cause search for the formation conditions of individual conflict situations. Thus, the psycho-social counseling, as a low-frequency crises intervention, builds on socio-therapeutic intervention forms of psychoanalysis that take into account the role of "personal relationships [of people] with each other, [...] their economic and their living conditions" (Richter, 1978: p. 146) or "the interrelationship between private interpersonal problems and macro-societal circumstances" (ibid.). Within the framework of socially-oriented training institutes, psycho-social counseling can actively shape and contribute when the interrelationship between individual conflicts and macro-societal conditions are taken into account. The starting point of our research is a reflection on the life situation of emerging adults who have been supported by a vocational training measure and by psycho-social counseling. It is not the efficiency of this practice but the self-concept of the participants that is crucial for our argument. Based on our empirical findings we engage in the discussion on identity and emerging adulthood of socially deprived people. Psychoanalytical development concepts of identity in the emerging adulthood are particularly fruitful as a background for interpretation in the context of vocational qualification measures if they take into account the living conditions and the social milieu.

First, we'll unfold the theoretical approach via the concepts of "identity development" and "emerging adulthood", whereby one builds upon the other. In later sections of this article, the methodological approach will be presented. The identity development in emerging adulthood will be interpreted case-specific based on three illustrative case studies. Commonalities in these unconventional life plans emerge. The results of the empirical research with respect to the becoming of an adult in a vocational qualification measure are discussed in the last section.

\section{Theoretical Background}

\subsection{Identity Development during Adolescence and Beyond}

Erikson's epigenetic development model, the focus of which is on the upheavals taking place during adolescence, including the physical, continues to lead the way in identity research (Keupp, 1999: p. 25f., Seiffge-Krenke \& Beyers, 2016). The development phase of adolescence is associated with numerous radical changes of various kinds. In the course of puberty and the following adjustment 
processes taking place, from a pediatric-biological view, the focus is on physical maturing processes and from a neurobiological view, it's on the neuropsychological restructuring processes. In the view of pedagogy and developmental psychology, the term adolescence emphasizes the processes involved in the psycho-social maturing of the individual. Yet he frequently differentiates these too much from the physical maturing of the body and sexuality, from which new, intensive psychological and social demands are made of the young people (see King, 2013: p. 30). Through transient identifications and dis-identifications, the process of identity formation is initiated (Erikson, 1973: p. 140). This focuses on the ability and the trust that an internal consistency and continuity will be achieved. In different developmental phases, also depending on historic socio-economic circumstances, different demands arise for the attainment of an ego-syntonic identity. Central for personal development is the resolving of crises; in each case arising at a specific stage through specific problems. The location of the central identity-building processes, for example, shifts in the adolescent stage (ego-identity to ego-identity diffusion) from the family of origin to peer groups.

The scholastic development and the vocational orientation are already dealt with by Erikson starting from childhood, from age 6 to puberty, (feeling of proficiency versus feeling of inferiority). In this development phase, achieving a basic feeling of competent activity, such as the experience of self-efficacy as well as reaching the adolescent goal of securing the ego-identity, plays an important role. In the subsequent stage of young adulthood, clarification of sexual orientation and the development towards family ties are described. A stable identity is then viewed as paving the way for successful intimacy in partner relationships (Seiffge-Krenke \& Beyers, 2016).

Through all of these changes, the interrelationship between a stable and an unstable integration of internal conditions in identity formation with the topic of partnership is reflected in the object selection: The handling of the final sexual organization as a weighing between a need for regression and a question of conscience culminates in the central masturbation fantasy (Laufer, 1980: p. 370f.), which decides whether one, acceptable for one's own-identity, sexual object-orientation develops or if the adolescence crisis is unresolved and must be kept open (Bohleber, 2014).

This progressive process of passing through age-typical life crises requires the reliable connection to lived feelings of authenticity in order to understand the respective crisis as overcome and to muster the self-confidence that subsequent crises can also be overcome:

"Erikson emphasizes that the identity formation in adolescence is not simply the sum representation of the childhood identifications, but rather the utilization of an integration process of old and new identifications and fragments, whereby the identifications with the parents are examined and new identifications with others (adults, friends, romantic partners) are developed. This process is turbulent and dangerous, which is why at all times and in all societies institutionalized psycho-social moratoriums or postponements existed in which young people 
could try out possibilities for self-discovery. This grace period has since been expanded quite a bit (Seiffge-Krenke, 2020: p. 376).

We will discuss this postponement in the next section. With regard to the necessary grace period during the transition into adulthood, the concept of identity offers, as conceptual leitmotiv following Erikson, the opportunity to weave together, in the sense of an elastic concept, the biological, sociological and psychological discourses. In the research following Erikson, according to Marcia (1966) identity is divided into the dimensions of exploration and commitment (Sevecke \& Resch, 2018: p. 618). The typology of combining both dimensions, "foreclosure, achievement, moratorium, diffusion", in research largely remains connected to this day (Seiffge-Krenke \& Beyers, 2016). The completion of a normative identity formation with a binding adoption of roles following sufficient, extensive exploration experience appears however, under the societal conditions of increasing functional differentiation, to be nostalgic (Krappmann, 1997: p. 80) and increasingly unusable. The increase in the identity diffusion Typus points to the difficulties with Marcia's typology and, moreover with the concept of an attainable, stable-coherent identity under the currently existing socio-cultural conditions in the 21st century (Gilmore, 2019: p. 645ff.). Moreover, insufficient reference is given by Marcia, though with Erikson, to the body (Gugutzer, 2002: p. 29). Thus, one of the most promising advancements in understanding the transition from adolescence to adulthood is the independent phase of "emerging adulthood" introduced by Arnett (2004). As its moratorium has a completely different character, it is to be differentiated from adolescence.

\subsection{Emerging Adulthood: Identity between Adolescence and Adulthood}

Not yet arrived but somewhere in between: this is what young people from age 18 to about 25 - 30 say is their dominant feeling with respect to a multitude of topics. This concept of "emerging adulthood" proposed by Arnett (2004) introduces this stage of life, in contrast to adolescence, as a separate developmental-psychological phase quasi as another moratorium. Conceptually, the emphasis of a youthful adolescence moves toward adulthood, whereby "emerging adults" are to be seen as nascent, more specifically as soon-to-be adults.

When looked at as a societal process, between adolescence (10 - 18 years-old) and young adulthood (25 - 35 years-old), a temporal widening is seen since the 1970s; a new phase of identity exploration has appeared. The concept of adolescence, which became popular in the previous century, no longer flows into a matured adult identity, but rather into a new development phase which also presents new challenges for psychoanalysis. The present-day search for identity is qualitatively different from those advocated for in 20th century concepts of adolescence (see Gilmore, 2019: p. 640). Three interconnected developments are the main reasons for this. The age that adults are having their first child has shifted by more than ten years from the 20ies to the 30ies (1). A firm career perspective is frequently not attained until the end of the 20ies (2) and due to 
cultural and social circumstances, longer training periods are necessary to meet the requirements of increasingly complicated work activities (3). The transition from "jobs" to long-term career paths and from fleeting love affairs to a permanent relationship and parenthood is happening later and later. Arising from this is a separate life stage at the age of 18 , lasting from 18 until (at least) 25 years of age that is termed emerging adulthood (Arnett, 2004).

This long period can be characterized on the basis of 5 interconnected criteria (see Gilmore, 2019: p. 638f.): In this precarious phase (1) of identity exploration (2) emerging adults feel torn between the poles of adulthood and childhood (3). They are facing a sense of unlimited future opportunities (4) and are, above all, self-referential (5). To take responsibility for oneself, make one's own decisions independently from parents and to become financially independent are the most common goals of emerging adults. Emerging adulthood is thus a processual counter-model to results-oriented transition research that sets the becoming of an adult to adulthood as a married person with a child or the desire for a child as well as a permanent position in the business world. This phase also differs from adolescence, which is connected to puberty, the parental home and school. The competing terms late adolescence (e.g. Salge, 2018) or post-adolescence (Blos, 1962) seem inappropriate as they were developed during a time when, nowadays atypical, early career decisions and parenthood took place during one's early 20 ies (see also King, 2020). As a new development stage of personality, emerging adulthood occurs immediately after adolescence. Both phases have at their core a grace period or moratorium. The type and the objective of exploration in the adolescent living environment influenced by changing pubescent bodies in the parental home and at school is significantly different from the demands made of emerging adults, who are no longer required to attend school, have moved out of the parental home and need to seek their own working and learning environments. Emerging adulthood, too, takes place within the socio-structural processes of generativity. Thus, the unlimited possibilities subjectively felt by emerging adults are to be set in relation to the social structures that can promote or also restrict identity exploration, which may in part offer undesired and sometimes also unused support, and so some support may be opposed by emerging adults. By also taking the generational as well as the socio-structural fault lines into account, through the term generativity the emerging adulthood concept thus gains a background upon which emerging adults' individual possibilities are played recursively when they crop up in their everyday living environment. Whether societal constraints prevent a psycho-social moratorium between adolescence and young adulthood is the subject of controversial debate (Arnett, 2016). It is debatable whether the criteria for emerging adulthood are sufficiently embedded in the everyday reality of more financially disadvantaged families (Silva, 2013). Moreover, some voices call for the body to be more strongly considered in this phase (e.g. Nelson et al., 2018).

Is it possible then with the help of the developmental-psychological concept of emerging adulthood to understand and explain the identity development of 
young people in vocational qualification measures?

A lack of social stability, which in the background also became noticeable in those we interviewed, makes it more difficult to take risks such as deciding on a course of vocational training or committing to a permanent partner. In social hardship situations, young people tend to erect a "hardened self" (Silva, 2013: p. 95ff.) that whenever possible avoids commitment to others: a phenomenon that Sally Peters can also show with emerging adults in Germany:

"Those affected constantly experience accusations of laziness and reluctance and their problems are not analyzed within the context of macro-social developments. Some examples of this include deepening poverty dynamics, widespread youth unemployment and exclusion from an educational system that, despite its rhetoric of inclusion, has little to offer that is helpful. As a result, young people have, in part, already incorporated society's expectations and criticize other young adults for their misconduct." (Peters, 2017: p. 65)

With the longer exploration phase, it appears that new inequalities occur in which autonomization opportunities, even socio-structural, are delayed, when the rent for the first own apartment becomes unaffordable, as well as when phases of no vocational training options and unemployment become longer and longer (King, 2020).

Body image and body consciousness tend to have a large influence on identity formation in this phase and yet with Arnett are hardly emphasized (Nelson et al., 2018: p. 1160). The satisfaction with one's own body tends to increase, after surviving puberty and adolescence, during emerging adulthood. Dissatisfaction with one's own body during this phase, on the other hand, is closely linked with identity diffusion (ibid.), as body image is connected with the topics of partnership and intimacy.

\section{From Metric Space to Individual Case Study}

\subsection{Case Selection}

Interviewees were recruited from among the participants of a study being conducted since 2013 on general and health-related life satisfaction with two measuring periods taken at an interval of at least 6 months (Schäfer et al., 2020). In this study, participants in a vocational qualification measure from between 15 and 27 years of age $(M=20.5 ; S D=3.9)$ were interviewed. For this study, based on the measurements, relative changes over time in the life satisfaction of 134 persons were initially depicted in five areas and then 10 representative cases were selected for the theme-centered interviews (Table 1). From the 10 interviewees (20 - 27 years-old), 7 were given psycho-social counseling, 6 emerging adults already had one or two children of their own, 3 interviewees were participants in a transition measure at the time of the interview, one person had already finished her training, 5 were in outplant (external) pedagogically supported training and one person was trained in the non-subsidized labor market. All ten interviews were recorded, faithfully transcribed and an in-depth hermeneutic evaluation performed. 
Table 1. Changes in the life-satisfaction of the interview partner.

\begin{tabular}{cccc}
\hline & $\begin{array}{c}\text { Increase in } \\
\text { health-related } \\
\text { life satisfaction }\end{array}$ & $\begin{array}{c}\text { Decrease in } \\
\text { health-related } \\
\text { life satisfaction }\end{array}$ & $\begin{array}{c}\text { Almost } \\
\text { unchanged }\end{array}$ \\
\hline $\begin{array}{c}\text { Increase in general } \\
\text { life-satisfaction }\end{array}$ & 1 (Clara) & 2 & 2 (Ronja) \\
$\begin{array}{c}\text { Decrease in general } \\
\text { life-satisfaction }\end{array}$ & 3 & 2 (Tom) & \\
\hline
\end{tabular}

Three exemplary cases are extensively presented below. They are listed in the table with anonymized names. The personal data has been changed for all interviewees. The research with case presentations has been authorized by the Ethics Board of the Department of Medicine at the JLU Giessen, Germany (Ethikrat des Fachbereiches Medizin der JLU Gießen) (Procedure number 255/13). The interviews are based on the work of a psycho-social counseling office for young people, which is supported within the frame work of the program "Qualification and Employment of young people in Hesse".

In selecting our interview participants, we took persons into account who have participated in a so-called transition measure for at least 6 months and could be stabilized. In this way, the study considers only those young people who have pursued a transition measure over a longer period of time. For subsequent research, it would be important to compare the persons who benefited from the transition phase offerings with those who broke off the measures in frustration. Otherwise, statements made regarding this setting would be meaningful only with regard to those participants benefiting from the training measure.

\subsection{Theme-Centered Interviews}

The interviews were designed as biographical narrative interviews (Küsters, 2006) in which the interviewees would be asked to talk about their time in the vocational qualification measure. In the theme-centered interview, the emphasis is on the narration and the evaluation of one's own life-story. Moreover, free association is revealing within the meaning of a socio-theoretical reformulation of psychoanalytical terms by way of the in-depth hermeneutic interpretation method. In this, the individual person that the focus is on is not hereby determined by social constraints or as the representative of a group, rather, as with all "research from the standpoint of the subject" (Ittner, 2016), it is a matter of "understanding an independence of mind relating to the framework conditions in a relationship of conditional freedom, always including subject-related particularities and nonetheless is an expression of the fundamental sociability of the subject" (ibid, p. 24). What meaning those interviewed give to the biographical station in the qualification measure between school and vocation in each individual case, what possibilities for action they elicited therefrom and what arguments they name to support their own decisions, can only emerge from the perspective 
of a subjective standpoint.

The in-depth hermeneutic method reconstructs forms of interaction. With its focus on memory traces, it links the dimensions of corporeality and the social. It approaches these motifs in three steps: the logic of what has been said, the mood during the interview and finally, the scenic aspects (König, 2019). The latter includes psychoanalytical categories, hence unconscious, that becomes visible in irritations, in transference and counter-transference (ibid., p. 18f.) as well as in the desire of the interviewer and of those interviewed. With this procedure, the interview protocol is to be understood as a representative framework of symbols that links logical and psychological layers of meaning with scenic information. In order to penetrate the latent levels of meaning without succumbing to the bias of the subjective view, the scenic aspects of the material were identified in an interpretation group; guided by a clinically experienced psychoanalyst and by reflection on, as unfiltered as possible spontaneous reactions.

In the following section, we provide page numbers and not line numbers in our references for reasons of clarity.

\section{Representations of Biography in the Theme-Centered Interview}

Ronja arrives at the interview together with her psycho-social counselor. Her hair is cut short and her figure is like that of a strong handyman. The greeting proves difficult as Ronja has turned her face away. She sought assurance that the counselor would still be on-site when the interview is over. Ronja's initial reaction then was mistrustful when asked to tell her story; she repeated several times that "if I were to tell you everything, we'd still be sitting here in five weeks" (Transcript 1: p. 2).

Ronja was born an identical (monozygotic) twin. The relationship with her mother was ambivalent and her childhood was characterized by a familial separation/split dynamic. The sister was the favorite child; she however was the black sheep of the family. She reacted by turning away from the family: "If one isn't accepted, one will just have to build one's own little world" (ibid., p. 16). Two experiences in particular stand out: At age 13, the mother "expelled" her to a children's home (ibid., p. 11); shortly thereafter, however, she called upon Ronja to return home. There, she soon became pregnant and the mother pressured her to abort the child. This behavior of the mother contradicts the expectations placed on her today: "[...] I will only then be accepted by the family when I come home with a child" (ibid. p. 13). Since the loss of her child, she has the feeling "of quietly being stuck in the wrong body" and the phallus evokes feelings of disgust in her, yet at the same time, she has developed the wish to be a man (see also ibid., p. 22). She traces the consumption of hard drugs, self-harming and suicidal behavior, rapidly changing sex partners and the onset of feelings of deep depression back to the loss of the child. She had tried desperately, to make "it $[. .$.$] not hurt so much anymore, when one is rejected by the$ 
family" (ibid.). At present, in addition to depressive moods, she suffers from recurring abscesses. Only "when it gets really bad" will she let them be treated (ibid., p. 7).

Participating in the vocational qualification measure has helped her to structure her everyday life. She perceived the psycho-social counseling, due to the relationship with the counselor, to be very positive and trusting. She believes that "I wouldn't [...] be sitting here any longer today if there wasn't the counselor earlier" (ibid., p. 30). Today, she is completing an outplant (external) training measure and would like to take the German master's examination (Meisterprüfung). She and her significantly older female life partner wanted a child that Ronja wanted to give birth to.

Carla comes to the interview on-time and in work clothes. She again states her fear, despite reassurance to the contrary, that the Youth Welfare Office would have access to the audio recording. When Carla vividly talks about deeply burdening experiences, it is difficult for the interviewer to bear the feelings that arise and assume the therapeutic role.

Carla is the second oldest out of a total of four sisters. Since she was eight years old, she has been in "14 homes and psychiatric wards" (Transcript 2: p. 3). She has also tried to take her life. Her family has never supported her, on the contrary, there were only accusations made against her: "[...] if all I am doing is breathing, I'm doing it wrong, which is actually why I don't go home anymore and I pretty much live my own life" (ibid., p. 10). She was not only the "black sheep" (ibid., p. 9) for the parents, but also for the sisters who would always "stick together" (ibid.). They earlier did not want to play with her, giving the reason that she was adopted. The relationship with her mother has always been ambivalent. On the one hand, she could never tell her mother about her condition. There was virtually a prohibition against "talking about my psyche" (ibid.). On the other hand, the "mother [had] a good heart" (ibid.) that she could not show because she is "also [!] mentally ill"(ibid.). The relationship with her biological father was characterized by sexual abuse (ibid., p. 3f.). After the separation from the father, Carla's mother met her later step-father, who Carla really liked. The biological father was "only my begetter" (ibid., p. 20), the step-father was however her "real father" (ibid.). Following the sudden death of the step-father, she "let herself go with drugs [...]" (ibid.), preferring cannabis, which was for her "a steady friend" (ibid., p. 6). She developed depressive feelings, began to self-injure and tried to take her life. The consumption of drugs not only led to gaps in her memory (ibid., p. 1), it also meant that for nearly "ten years she had perceived no feelings" (ibid., p. 11f.). At that time, she conceived two children with different men. Due to the continued use of drugs, the Youth Welfare Office took custody away from her.

The Job Center procured a vocational qualification measure for her, in which she began to make use of psycho-social counseling. Through the trusting relationship with her counselor, she was able to stop taking drugs. She also stopped 
cutting herself when she'd find herself in conflict situations (ibid., p 13). She reduced her tendency to react impulsively and she has now begun a training course in carpentry, her area of work and actually "feels like working" (ibid., p 14).

Tom arrives very punctually to the interview appointment. His cheerful manner and his muscular body are particularly striking. He tries to take control over the conversation by asking the interviewer about the goals and results of the project. In the end, he complied with the request to narrate and openly reported about past events and his current life situation. The atmosphere is jovial. Tom tries hard to get the interviewer to laugh.

Tom was born into his parents' tension-filled relationship. The father had been absent. He and the mother had often argued during his childhood, until his father was "thrown out" due to his alcohol issues (Transcript 3, p. 3) when Tom was 9 years old. The father then moved with Tom and three younger siblings to a two-room apartment. There, the father continued to consume a lot of alcohol and when he came home late at night, he would often hit Tom multiple times. Tom had to tend to his younger siblings. His academic performance suffered greatly at that time. He was the black sheep of the family (see ibid.).

When he was eleven years of age, "[Tom] was the only one who was allowed to go to the children's home" (ibid., p. 5). There, he came to terms with the "alpha-animal structure" (ibid.) and only left his room during meal times. At 18 years of age, he moved in with his mother, step-father and his (step)-siblings. There, he felt he was in a better position (see ibid., p.4) than with his father. He did, however, complain that he didn't have sufficient personal privacy there (see ibid., p. 23).

Through mediation by the Job Center, he had started a vocational qualifying measure. There, a conflict quickly arose with his two expert instructors who had given him conflicting work instructions. "Both of the [expert instructors] come from time to time, they came and said that everyone here has his personal technique, how one does things, you must find your own. Mine is that and that. The other boss says, his is that and that" (ibid., p.1).

After he completed the measure, he began a medical assistant training course. Today, he has lots of enthusiasm for the work on and with the people. Here, another conflict with a work colleague was in the making. He feels the relationship to his superiors, however, is both professionally as well as personally good. In the psycho-social counseling, above all, he talked about acute conflict situations and thus is better able to structure his daily life.

\section{Wounds of the Past: Latent Dimensions of Conflict}

\subsection{Ronja: Embodiment of Personal Conflicts}

Ronja's drastic way of speaking, her rejection of everything masculine while simultaneously appearing masculine and her risk behavior and her tie to family and the counselor come to the fore. There were also several productive irrita- 
tions with the thematization of Ronja's twin sister and her sexuality. The auto-aggression and the associated conflicts surrounding the sexual identity development are a central motif of the biographical narrative. The diverse biographical experiences and individual behaviors solidify herein. She emphasizes that she "is stuck in the wrong body" (Transcript 1, p. 3). The body appears as a shell that falsely represents the interior. Bodies are maneuvered like objects, defined by repulsion and embodiment. Severe and emotionally painful experiences should be regulated via auto-aggressive behavior (self-cutting injuries, excessive drug consumption et al). The sexual identity development takes place in this conflicting environment of the body as a medium for regulation of emotions and relationships (Burgermeister, 2019, Laufer, 1980). As a mirror image of the biographical experiences, it is to be interpreted as fundamentally conflict-laden.

Ronja's attempt to regulate emotions through self-cutting injuries and to attain a reduction in tension, points out, however, the symbolic presentation possibilities. Injuring the skin, which as an organ of the body demarcates the internal (the feeling world, internal reality) from the external (the environment, the reality), externalizes the own body as an object in the world. Instead of integrating urgent emotions into one's self-experience, a drastic form of physical acting-out is chosen. Due to the splitting-off of the somatic sphere from self-experience, a deliberate confrontation with one's own emotions is avoided. Physical pain occupies the internal conflict-situation arena. A long-term solution to emotional conflicts is thus not possible as no access to a successful self-concept can be reached in this manner.

Noteworthy is Ronja's denial with regard to taking care of the abscesses. It puts her own life at risk and the behavior is rationalized by claiming she doesn't want to risk endangering her training with a hospital stay. Her physical existence is being risked for the benefit of developing a vocational identity. Problem solving practiced in this manner highlights the individual difficulty of reconciling the identity-relevant dimensions (in the form of an internal working model) with each other.

The loss of her unborn child represents an urgent breach of trust that "will accompany [Ronja] her entire life" (Transcript 1, p. 10). In the safe, support-providing arena of psycho-social counseling, Ronja is provided support in her battle for something stable and enduring. There, she entered into a continuous, trust-based interaction relationship, which is presumably different than her previous relationship experiences. When "things get really tough now and again, since, all I have to do is phone and someone will listen to me" (ibid., p. 28).

\subsection{Carla: A Feeling of Security and Substitution}

The conversation left its mark on the interviewer in the form of a counter-transference dream (see Zwiebel, 1984):

"I'm sitting in the bathtub when out of the depth of the water, arose a sinister, scary figure that resembled a life-size sponge. I had the feeling that she/it wanted 
to drag me down into the depths."

The interviewer reacted to the emotional content of the biographical narrative. The Janus-faced nature of the drugs as a substitute relationship figure becomes clear. Emotional tensions can only be regulated temporarily at the expense of one's own personal development. Metaphorically speaking, the sponge not only absorbs tension-filled conflicts, it also absorbs all emotionality. In the dream content, a need for regression became evident, from which the interviewer recoiled. In the interpretation group, the image of an embryo in the mother's belly came up. In the attempt to understand the drug taking, above all, it is the subjective attitude towards life, of not belonging to the family, a mother who wasn't receptive to the concerns and fears of her daughter, sexually traumatic experiences and the death of the much loved step-father that becomes the focus of attention. The drug consumption fulfills the function of reducing emotional tensions, so they don't have to be experienced as internal, threatening conflicts. Ronja regulates this way in relationships with emerging closeness-remoteness issues, autonomy vis-à-vis dependency needs and idealization desires vis-à-vis abasement tendencies. The drugs are "a steady friend" (Transcript 2, p. 6); a substitute for a poor relationship with the mother, in which conflicts and fears were not allowed to be discussed. The longing for a responsive mother-figure becomes clear as she emphasizes the positive side of taking drugs: "[...] then everything in the world was totally good and nothing could hurt [me]. [Everything] was full of harmony and love", "[the drug] was everything for me" (ibid.).

The reported social relations are marked by breaches of trust. It is only in the relationship with the step-father, which tends towards idealization, that a relatively stable object-relationship appears to be discernible. The distinction between the biological father and the step-father is noteworthy. The biological father comes across as a physical inferiority and a trust abusing, aggressive man without even a single positive father function. In contrast, the sudden death of the step-father, with whom she maintained a close relationship, was experienced by Carla as "a heavy blow of fate" (ibid.), following which she "totally let herself go with the drugs." (ibid., p. 21).

The relationship with the psycho-social counselor is important for Carla's personal development, she says: "[...] for the first time, I really totally confided [in someone]" (ibid., p. 14). She portrays a changed emotional experience since she stopped taking drugs: "[...] for ten years, I perceived no feelings. [...] it feels as if you are feeling for the first time. Hate, love, how do you handle these things?" (ibid., p. 11). A reflective handling of these emotions is possible through the psycho-social counseling, so that the drugs, as emotion-regulating medium increasingly give way to the individual's growing ability to integrate ambivalent emotional states.

\subsection{Tom: Authoritarian Breaks}

The adolescent conflict "ego-identity vs. ego-identity diffusion" in this case is of 
crucial importance. Concomitant potentials for critical situations that manifest themselves in this phase arise in relationships with persons of authority. With regard to Tom's emotional development, the violence he suffered from the father and the neglect during childhood (see Transcript 3, p. 4) are not to be underestimated. Moreover, there is significant parentification: Tom took over caring for his younger siblings; his own emotional needs were disregarded. Tom's father image lacks both comprehensible authority and emotional stability. The only paternal authority is physical superiority in the form of physical violence: The "alpha-animal structure" he experienced in the children's home (ibid., p. 5) resembles a hierarchical social order based on the "law of the jungle", whose preservation is guaranteed through threatened use of violence. No room remains for individual self-development. In the end, Tom succeeds in adapting to this oppressive structure: Membership in groups provides protection from the "alpha-animals": "When I'm at the school, I mostly hang out with my guys in the smoking area $[\ldots]$, didn't have any problems that way" (ibid.). The similarity between the alpha-animal structure and Tom's relationship with his father lies in the looming threat that violence will be used. The presumed alpha-animals are experienced as authorities at the children's home, where they resemble the father as perpetrators of violence. In the interpretation group, the following image solidified: For his protection, Tom "armored" himself by building a muscular body. This strategy was also observed in other transitional measures (see Zahradnik, 2018).

The consolidation of an occupational identity is, up to the present day, difficult due to the background of individual experiences. Irreconcilable work orders from expert instructors, represent for him the hated arbitrariness of authority. The orientation towards what has already been given makes it possible for Tom to construct his own identity. This orientation, however, gets in the way of Tom's training context of individuation towards identity as a tradesman.

The description of the working relationship to his bosses at the current training facility indicates Tom's specific approach with female authority figures, namely sexualizing the relationship.

Tom: " $[\mathrm{M}] \mathrm{y}$ relationship base actually always consists of people who are older, firstly, the [superior] has a friend and secondly, certainly not with work colleagues" (ibid., p. 15).

At every identity-forming stage, the fixation on a person of authority eventually becomes apparent. The individual adaptation to given structures helps self-assertion. Tom not only follows instructions, he also opens the scope for actions thanks to his knowledge of the inherent logic of authority-conditioned practice.

\section{Unconventional Life Plans}

Before we can discuss our results, we would like to condense them into a central motif of the biographical narratives, namely how, despite their life-story back- 
grounds, a personal utopia can be created that is worthwhile pursuing. This must not be misunderstood as idealizing reinterpretation of one's own life. According to the findings of a recent study on identity in the life-cycle by Margarita Bakracheva (2020), what really moves emerging adults is not the quest for achieving identity, which still classical theory formulated. Their realistic aim in terms of identity development can be seen in "constant search and exploration" (ibid. p. 10) and not to end in resignation. Studies like this suggest that in the past two decades developmental stages of moratorium were found more often than the status of identity achievement. Because of this ongoing quest for exploration, to answer the question of identity, of who one really is, becomes harder, and research has to take into account these difficulties. In truth, what matters to the emerging adults is substantiation of their future-orientation and their confidence, but also to be able to make it clear to the interviewer how progressive personality development during the vocational qualification measure period can be initiated.

In all three cases, the family histories, which are unsteady, characterized by neglect and potentially traumatizing, with temporary stays in compensatory care institutions, are perceived by the interviewees as degrading. Even as they jointly characterize themselves against a background of their individual biographies as the black sheep of the family, they are nonetheless actively able to create freedoms, room to maneuver, for themselves. Strengthened by the psycho-social support, they developed logically coherent and future-oriented life plans, which they tried to implement through the attainment of concrete interim goals in continuous steps, for example by transitioning into vocational training:

Ronja sees herself as an outcast. She lived out the outsider role turned away from the family by "hanging out" for days on end. In her partnership with an older woman and a mutual desire for children, her unconventional life plan was solidified. Her goal to complete the training serves to secure this lifestyle.

The objective of Carla's way of dealing with her body is mainly the pacification of emotional conflicts. The excessive drug consumption serves to form the identity and to filter reality. The handling of emotions, people and the machines at the workplace: Everything experienced is related to the drugs. Carla quitting her drug taking forms a milestone in her personal development.

Tom identifies himself with structural everyday requirements. An inner differentiation of external boundary limits is very hard for him. Again and again, the limits blur between family and outside-of-the-family relationship constellations. Authority and arbitrariness lie dangerously close to each other, so that he always has to satisfy himself of the limits between the two. The necessary transition process is blocked through this fixed integration.

In all of the biographical narrative interviews, we see that the entanglement with the own parental home and the care institutions is too conflict-laden to allow sufficient room for the development of independence. Among the interviewees, the specific adolescent lines of conflict between adolescents and the paren- 
tal home are dragged into the emerging adulthood phase. They hinder, e.g. through unsuitable projections of family conflict situations to partnerships and work, identity exploration and the development of independence, as defined by Arnett. Our evaluation of the interviews also emphasizes the significance of body consciousness for identity formation in emerging adulthood:

Ronja's physical concept of identity, in her orientation towards health as well as partnership, threatens to massively come into conflict with the vocational-status-based identity formation.

In Carla's narration, her physical body is initially absent. It then came to a search for the physical, which had a strong effect on the interviewer's emotions.

Tom, on the other hand, by building his muscular physique (Anzieu in accordance with Brosig and Gieler, 2016) is not searching for the split, but rather the coherency, as the first step in the consolidation of his identity in order to meet the threat from violent authority at all levels.

It also becomes evident that in the course of psycho-social counseling, providing a social-therapeutic option (Richter, 1978) is beneficial for identity formation. Uniting all three cases is the self-confidence in their own decisions, which requires an ability to delay gratification and which will not reap rewards until a future date.

\section{Discussion}

The biographical accounts and, by means of the in-depth hermeneutic reflexion derived therefrom, the case-based wrestling surrounding the solution to personal crises serves in the following section to empirically examine, in the context of the theoretical discussion, the posed question: Can the identity development of young people in vocational qualification measures be understood and explained by means of the developmental-psychological concept of "emerging adulthood"? In addition, we also take a critical look at the dependency of this development on social constraints and one's own body-image.

\subsection{The Impact of Trauma on Transitions from School to Work}

The exemplary case presentations of three participants in a vocational qualification measure are shaped by the memories of potentially traumatic experiences and the realities of life. The relationships with primary caregivers are depicted as unstable and quite disturbing. They continue to have an effect to the present day. Due to their conflictual character, these early experiences still remain relevant to actions in the subjective everyday reality of an emerging adult in a vocational qualification measure. They play a large role in the (self) narrations of the emerging adults and often, in the sense of a spontaneously occurring transference event, an arc is drawn from dramatic early relationship experiences to interactions in the (repair or construction) workshops. As a child, the experience of being removed from the family and placed in a children's home can e.g. seep into the experience of vocational transitions. The global self-concept (in particu- 
lar, the own individual's convictions and their assessment) and the occupational (training and vocational) plans for the future are, from a psychological point of view, strongly bound to the inner object-representations of the primary caregivers. The interviewees therefore have difficulties in finding an ego-syntonic "compromise" between their own vocational choice and their future-related wishes, hopes as well as goals and the presumable (demands made by) requirements of the inner objects. The interviewees are painfully bound to the traumatic failure in their families and are hardly able to shed this compulsively repeated identification: While bound to dark traumatic memories, it is difficult to mobilize one's own creative dynamics. In the interviews an overweighting of vocational-related narratives compared to the thematization of individual vocational-related development in the qualification measures clearly points out this intra-psychic tension field that spans the poles between autonomy and object-linkage. It is clear therefore that the emerging-adult-age development phase of our interviewees is permeated with problems and conflicts that were current in their earliest to early development phases.

In this, appears the specific vulnerability of emerging adults who experienced neglect and/or violence in their childhood. In their professional advancement, they also remain vulnerable as they had the incisive experience of how quickly situations suggesting safety and commitment can turn into danger. These massive disappointments date back to early attempts to find trust in others and to experiences of successful self-efficacy and personal initiative.

\subsection{Constraints on Vocational Development}

Contrary to our introduction of Erikson's distinction between the three phases of adolescence, namely before, during, and after, the interviewees in their self-narratives draw on conflicts from much earlier to represent or make us understand their current situation as emerging adults. Moreover, study participants are presently in different positions with regard to their concrete generativity within the family. A number of interviewees have no experience with children of their own; a remarkable number are already parents or already have terminated a pregnancy in the past. Nevertheless, they appear insecurely attached in partnership as well as in work, which suggests that earlier transition criteria (firm attachment to job and partner) do not automatically occur during the early 20 ies, even if the emerging adults have already become parents. Belonging to the subject of generativity is the societal ambivalence between social welfare and successful formation (in the comprehensive sense of personality formation). On the one hand, social advancement, creativity, personal initiative, mobility and flexibility are demanded of young unemployed people by society. On the other hand, emerging adults younger than 25 and dependent on social welfare are prevented by law (in Germany) from moving out of the parental home (Figlestahler, 2018) as parents can then expect a reduction in social benefits, meaning if these children become independent, it usually means the parents can no longer 
cover housing costs through the Job Center's financial assistance as the number of people in the joint household "community of need" is reduced. Due to the conditions of unemployment benefit II (ALG II), emerging adulthood is often normalized by external constraints and also shaped by outside forces. The excesses in the personal stories show extremes such as criminality and suicide attempts, which is, not least, evidence of the much too small leeway provided to emerging adults in this socially marginalized situation. And yet, the need for exploration breaks through. The same applies to the paradoxical mission of vocational qualification measures, which on the one hand is supposed to help young people with their vocational orientation, and thereby namely gain experiences with the day-to-day processes of individual professions. On the other hand, however, they don't come voluntarily, but rather under an obligation subject to sanction, which is way too keen to send individuals through the educational plan of measures that build on each other, but without providing adequate resources. Remaining unanswered is how, within this framework, the fundamentals for building a vocational identity as a component of a broader, personal identity can be applied (Discher et al., 2017). In the search for how to handle this situation, an ambivalent situation arises for the emerging adults that is reminiscent of Derrida's (Miller, 2006) coining of the term destinerrance. An arrival is not possible, even more so during the transitional phase, without thinking about departures, and thus the attainment of an arrival as a goal is misleading. The emerging adults are to be qualified in order to again leave the transitional phase. They consequently utilized the psycho-social counseling and the interview to discuss individual conflict dynamics and to subjectively structure the sometimes chronicized inner stresses in a meaningful way. The psycho-social counseling, provided in a protected and trusting atmosphere, is for our emerging adults indeed the precondition for being able to use the "institutionalized psycho-social moratorium" (Seiffge-Krenke, 2020: p. 376) for themselves. Individual plans for the future, for individuals themselves and here especially relating to one's own career choice can develop only in the course of personal stabilization aimed at achieving an inner balance. The counseling integrated with the qualification measure is a valuable social-support resource on the path to the non-subsidized labor market, as it urges them to focus on the subjective instability, the identity exploration, the individual possibilities, the in-between-ness and thus to self-focusing. Through professionally-guided reflexion, it thus sustainably addressees the conceptual core of emerging adulthood and supports emerging adults in the exploration of their future possibilities. The model of the developmental phases, which is oriented toward ego-syntonic syntheses, nevertheless proves to be insufficiently informative with regard to the manifold biographical breaks and unresolved conflicts, especially with the family of origin.

\subsection{Widening the Concept of Identity Development}

One way of escaping the rigidity in the epigenetic model of developmental phas- 
es is based on a reflection of the "anchoring of the soul in the corporeality of the human being" (Bohleber, 1999: p. 526). Finally, a changing body connects the various development steps, is always involved in social exchange, and is an insurmountable part of the identity formation processes. In our interviews, the subjective body awareness forms an important reference point for one's own identity. A decided consideration of the corporeal (in the sense of the habitus concept as body-memory [Bourdieu] or as skin-ego concept [Anzieu]) is a valuable addition to the identity-theoretical framework, although the abilities for mental representation in individuals vary considerably. The formation of routines of action and emotional self-regulation are bound to each individual's own physical sensations. Potentially traumatic childhood experiences restrict the individual's scope of action for the adjustment of routines represented in the body memory. The inner struggle for a good development of the personality, as described in identity theory, remains colorless if it is not mapped in the context of the acquisition of a subjective habitus (Bourdieu, 1997). With the habitus concept, emphasis is placed on the things the individual stands for, that lift the individual up, or bring him down, or curl up into a ball (see also Gugutzer, 2002: p. 112). Bourdieu (1997) also shows the dependence of identity formation on its social context, which Erikson, Arnett and his critics also point out (Arnett, 2016). Bourdieu however goes beyond Arnett's approach. He ties the habitus and thus also the body to the social field, as a place where particular routines emerge, without however, as with Erikson, the developmental-psychological clarification of the subjective access to one's own position in the field (see Wollenhaupt, 2018). The precarious life situation in qualification measures is thus subject to field-own rules of play (see Section 5 above).

\subsection{On the Scope of the Emerging Adulthood Concept}

The development-psychological phase of emerging adulthood formulated by Arnett presents a quite fruitful concept for the understanding and the explanation of identity development in emerging adults in vocational qualification measures. The integration of emerging adulthood with overarching theoretical models such as generativity is also fruitful as we have seen in our case applying it to qualitative research. The concept of a distinct development phase for various disciplines is also important (such as psychoanalysis, sociology and social work). It can certainly be utilized to better understand emerging adults in vocational qualification measures. A layer-specific actualization or concretization however continues to be advantageous.

In a notable discussion with his critics, Arnett highlights that the 5 criteria he posits (identity exploration, instability self-focusing, a sense of inbetweeness, perceived unlimited future possibilities, Arnett, 2016: p. 230) do not vary systematically in their extent with the social status of the interviewees. We will now explore this further. Based on our material, it is accurate to say that the interviewees oscillate between the extremes of adolescence and adulthood (with sub- 
stantial fluctuations), that namely they have the feeling they are "kind of in-between". They also strive to take on responsibility and make their own decisions, independent from their parents. They want to be financially independent so they can "go their own way" (identity exploration). In doing so, they describe a back-and-forth between complete self-abandonment and the turning point at which they were able to focus on their vocational training (instability).

For us, as well as for critics of Arnett, the assumption of perceived, unlimited future possibilities is inaccurate (Silva, 2013, King, 2020). The interviewed young people in vocational qualification measures are well aware of their precarious social situation (and eventually also implicitly, the institutional limitations placed on their actions and decision-making possibilities); they know that they are living a life on the margins of society. Despite multiple imponderables, they strive to find for themselves a position in the non-subsidized job market, to be hired and eventually also to be able to control their personal situation. Thus, the question about the category of unlimited future possibilities gives rise to an ambivalent picture in which the feeling of unlimited future possibilities at this life stage described by Arnett is, for our interviewees, dampened by many, in part, institutionalized restrictions and exclusionary experiences.

In particular, it is questionable whether the especially pronounced self preoccupation, according to Arnett, typical of emerging adulthood, applies to our interviewees. In making their decisions, they are not free enough from the influence and the challenging demands of the inner objects, leading to a confused access to the self as the unconsciously remaining identifications play a major role. The lack of self-care expressed in the narratives, the internal and external neglect, and the self-destructive tendencies suggest that this is less a matter of self-preoccupation in the sense of being confident to the point of over-confidence. Rather, these circumstances are an expression of a firmly anchored normative notion, namely that failure is to be expected in the face of various (training) hurdles and that consequently, successes are to be viewed skeptically. The persistence of the trust issue and the embodiment of social conflicts in the interviews restrict the development potential, so that interviewees, for the most part, lack trust in themselves and others, especially in people who are in the same situation as they are (see Peters, 2017).

Without a sensibility for social differences, the interconnectedness of the social as well as psychological needs of our participants would have been concealed. A real understanding of their personal situation can only be assessed as acceptably good when it reflects the fears of losing social status and the inner brutalization; namely the themes that come to the fore in the biographical narratives. However, due to the social distance, the danger of a paternalistic-patronizing access to that what people in the transitional phase supposedly need can still arise. If inter-connections in the inner experience between the interviewer and interviewee remain unnoticed, the interpretation of the biographical narrative results in the danger of denying the intensity of the existential 
problematic of emerging adults in the transition phase. To reject their ideas and needs as childish, dangerous or unworldly leads to a denial of social as well as the inner-psychological conditions relating thereto. Through this conscious alienation of others, the social responsibility for a labor market that knows how to integrate as many different people as possible recedes into the background. Likewise, also being suppressed is where do the expectations come from that emerging adults without any formal vocational training are confronted with. Contradictions in the narratives of social advancement and labor market opportunities are also portrayed by working adults, social scientists and therapists. Fears of stalled career development or unemployment and irrelevance, or not being able to meet job requirements connect the biographies of people inside and outside of working life.

\subsection{Retrospect and Prospect}

In the autobiographical narratives internal and external constraints on the development of identity were pointed out. Going through traumatic experiences and missing developmental goals in childhood affects the chances to cope with difficulties at the transition from school to work. Trajectories of life can be traced back to severe problems which occure in early life stages but shouldn't be grounded on a reductive psychologization. External constraints due to social deprivation and chaotic family relations shape biographies of those emerging adults who are facing risky transitions, too. A focus on habitual characteristics and bodily changes opens up a perspective anchoring in major challenges of the life stage emerging adulthood.

This understanding approach made it possible to make visible the individual conflict dynamics, potentials and biographically-based difficulties with respect to the personality development of emerging adults in a transitional measure. The theme-centered interviews let participants speak, providing insight into their world of thoughts and feelings, the focus is on the individual, who does not disappear behind the average of his group. This approach sometimes also brought the interviewer to the brink of threatening, although interesting experiences. The strength of this approach compared to purely quantitative-based methods is to thereby provide access to the interviewees' world through involvement. There is naturally also a danger in this: one should namely not get too involved and thus become blind and lose needed distance, without which returning to scientific discourse from the field will be blocked. The extent to which we as social researchers or therapists, given the fact of a middle-class socialization, are ready and can be ready to understand the realities of life of these people becomes clear in the safe spaces that are mutually opened up in the interviews. While the interviewer reassures interviewees the recordings will be handled responsibly, interviewees try to keep away from the temptation of excessive drug use and unbridled sexual life, which until the present day have cast threatening shadows upon them. The questions of to what extent these young people are actually pa- 
tients and not clients in counseling, to what extent this is a matter of milieu-specific habitus or tangible traumatizations, always also means what of the stories presented in the interview as well as in counseling wants to be, can be, dealt with and what is hastily discarded in the sense of abjection (see Kristeva, 1982) and remains effective in the background.

\section{Conclusion}

At the end of their compulsory education, even in a strong job market, many young people remain without any formal vocational training, some for a number of years. Our interviewees belong to a social group where it has been observable for decades that they need more time than foreseen to conquer the hurdle between school and vocation. Completed vocational training is one of the most important prerequisites for access to the labor market (Solga \& Menze, 2013). Vocational qualification barriers are often due to a complicated educational career and the dynamics of social exclusion processes, although they are also associated with the below-surface dimensions of biographically-determined conflict dynamics (see Freyberg \& Wolf, 2005). Our article outlines the importance of this below-surface dimension. Thus, it can be shown that the concrete family constellation is important and difficult to standardize, especially when issues such as neglect and traumatization in childhood are in the background. Such experiences have an impact on the current reality of life of those affected, who each have an individual level of coping strategies, and thus in the concrete research practice. They often make it more difficult to recruit and, in particular, to establish the necessary relationship of trust in the context of interview research that focuses on subjectivity. The confrontation with moving life stories in the interviews places high emotional demands on the interviewer, who should have certain characteristics such as empathy, sensitivity and the ability to avoid emotional entanglements. These abilities contribute to a trusting relationship with the interviewee in the concrete interview situation as well as to a meaningful reconstruction of the interview material. This research approach, which is based on a relationship of trust, ultimately aims at what the interview partner has become, at his individual life story as it is represented mentally. The interviewee constructs his biographical past in the interview situation by putting it into words and articulating it. Psychological developmental obstacles that arise early in life can thus come to the fore, which make the transition to professional life more difficult, but which cannot be specifically overcome in the daily routine of the measure. The reasons for this often lie in the structural and legal framework of the institutions that offer vocational training.

For emerging adults, a psycho-dynamically oriented counseling approach, in particular, provides an integration of experiences from early biographical developmental phases into the current structures of thinking, feeling and acting. In our interviews, consequences the emerging adults drew from their childhood also shimmered through repeatedly in their descriptions of current experiences. It 
is therefore worthwhile to use psychoanalytic approaches such as Erikson's theory of identity development and the more recent formulations that follow it to model the developmental phases of emerging adults in order to identify key points in the material that are of critical significance in the interviews as well as the counseling sessions with emerging adults in socially marginalized situations.

\section{Funding}

This article was self-funded. This article did not receive any funding from grants or other interested parties.

\section{Conflicts of Interest}

The authors declare no conflicts of interest regarding the publication of this paper.

\section{References}

Arnett, J. J. (2004). Emerging Adulthood: The Winding Road from the Late Teens through the Twenties. Oxford University Press.

Arnett, J. J. (2016). Does Emerging Adulthood Theory Apply across Social Classes? National Data on a Persistent Question. Emerging Adulthood, 4, 227-235. https://doi.org/10.1177/2167696815613000

Bakracheva, M. (2020). Identity in Adulthood-Stable or Flexible. Open Journal of Social Sciences, 8 , 1-13. https://doi.org/10.4236/jss.2020.84001

Beicht, U., \& Eberhard, V. (2013). Ergebnisse empirischer Analysen zum Übergangssystem auf Basis der BIBB-Übergangsstudie 2011 [Results of Empirical Analyses of the Transition System Based on the BIBB-Transition-Study 2011]. DDS-Die Deutsche Schule, 105,10-27.

Blos, P. (1962). Adoleszenz. Eine Psychoanalytische Interpretation. Klett-Cotta.

Bohleber, W. (1999). Psychoanalyse, Adoleszenz und das Problem der Identität [Psychoanalysis, Adolescence, and the Identity Problem]. Psyche-Z. Psychoanal, 53, 507-529. https://doi.org/10.21706/ps-53-6-507

Bohleber, W. (2014). Adoleszenz. In W. Mertens (Ed.), Handbuch psychoanalytischer Grundbegriffe (pp. 29-36). Kohlhammer.

Bourdieu, P., Wacquant L. J. D., Balazs, G. et al. (1997). Das Elend der Welt. Zeugnisse und Diagnosen alltäglichen Leidens an der Gesellschaft. UVK Verlag.

Brosig, B. , \& Gieler, U. (2016) Einleitung. In Idem (Ed.), Die Haut als psychische Hülle (pp. 11-24). Psychosozial-Verlag.

Burgermeister, N. (2019). Selbstverletzende Handlungen als Beziehungsdrama. In J. König, N. Burgermeister, M. Brunner et al., (Eds.), Dichte Interpretation (pp. 117-143). Springer. https://doi.org/10.1007/978-3-658-21406-7 3

Discher, K., \& Hartfiel AK (2017). Employable Youth-Employable Bodies? Körpererzählungen im Aktivierungsdiskurs [Employable Youth-Employable Bodies? Body-Narratives in the Activation Discourse]. FZG-Freiburger Zeitschrift für GeschlechterStudien, 23, 37-52.

Erikson, E. H. (1973). Identität und Lebenszyklus: Drei Aufsätze. Suhrkamp.

Figlestahler, C. (2018). Jugendliche und junge Erwachsene im Transferleistungsbezug. In A. 
Lange, H. Reiter, S. Schutter et al., (Eds.), Handbuch Kindheits-und Jugendsoziologie (pp. 253-262). Springer. https://doi.org/10.1007/978-3-658-04207-3 15

Förster-Chanda, U. (2020). Jugend im Risiko: Psychosoziale Beratung in der Benachteiligtenförderung. Psychosozial.

Förster-Chanda, U., Geist, C., Balser, W., Moser, V. \& Brosig, B. (2013). Innere Konflikte und Biografien von Teilnehmern einer Jugendwerkstatt. In S. Heike (Ed.), Psychosoziale Beratung in pädagogischen Handlungsfeldern (pp. 217-230). Psychosozial.

Freyberg, T., \& Wolff, A. (2005). Störer und Gestörte. Brandes und Apsel.

Gilmore, K. (2019). Is Emerging Adulthood a New Developmental Phase? Journal of the American Psychoanalytic Association, 67, 625-653. https://doi.org/10.1177/0003065119868680

Gugutzer, R. (2002). Leib, Körper und Identität: Eine phänomenologisch soziologische Untersuchung zur personalen Identität. Springer. https://doi.org/10.1007/978-3-322-90147-7

Hirschfeld, H. (2020). Macht und Ohnmacht sozialpädagogischer Hilfe. biografische Perspektiven auf pädagogisch begleitete Übergänge. Verlag Barbara Budrich.

Ittner, H. (2016). Methodik für eine Forschung zum Standpunkt des Subjekts [Methods for Research in an Approach to the Standpoint of the Subject]. Forum Qualitative Sozialforschung, 17, Art.10.

Keupp, H. (1999). Identitätskonstruktionen. Das Patchwork der Identitäten in der Spätmoderne. Rowohlt.

King, V. (2013). Die Entstehung des Neuen in der Adoleszenz. Springer. https://doi.org/10.1007/978-3-658-01350-9

King, V. (2020). Das Konzept ,Emerging Adulthood‘ aus jugendtheoretischer und zeitdiagnostischer Sicht [The Concept of 'Emerging Adulthood' from a Youth-Theoretical and Contemporary Diagnostic Perspective]. Diskurs Kindheits-und Jugendforschung, 15, 355-369.

König, H. D. (2019) Dichte Interpretation. In J. König, N. Burgermeister, M. Brunner et al., (Eds.), Dichte Interpretation (pp. 13-86). Springer. https://doi.org/10.1007/978-3-658-21406-7 1

Krappmann, L. (1997). Die Identitätsproblematik nach Erikson aus einer interaktionistischen Sicht. In R. Höfer, \& H. Keupp (Eds.), Identitätsarbeit heute (pp. 66-92). Suhrkamp.

Kristeva, J. (1982). Powers of Horror. An Essay on Abejction. University Presses of California.

Küsters, I. (2006). Narrative Interviews. Grundlagen und Anwendungen. Springer.

Laufer, M. (1980). Zentrale Onaniephantasie, definitive Sexualorganisation und Adoleszenz [The Central Masturbation Fantasy, the Final Sexual Organisation, Adolescence]. Psyche-Z. Psychoanal, 34, 365-384.

Marcia, J. (1966). Development and Validation of Ego-Identity Status. Journal of Personality and Social Psychology, 3, 551-558. https://doi.org/10.1037/h0023281

Miller, J. H. (2006). Derrida's Destinerrance. Modern Language Notes, 121, 893-910. https://doi.org/10.1353/mln.2006.0099

Nelson, S. C., Kling, J., Wängqvist, M., Frisén, A., \& Syed, M. (2018). Identity and the Body: Trajectories of Body Esteem from Adolescence to Emerging Adulthood. Developmental Psychology, 54, 1159-1171. https://doi.org/10.1037/dev0000435

Peters, S. (2017). Erwerbslos, überschuldet, wohnungslos ... In J. Schröder, L. H. Seukwa, 
\& U. Voigtsberger (Eds.), Soziale Bildungsarbeit: Europäische Debatten und Projekte (pp. 51-68). Springer. https://doi.org/10.1007/978-3-658-17016-5 4

Richter, H. E. (1978). Was ist Sozialtherapie? In Idem (Ed.), Engagierte Analysen: Über den Umgang des Menschen mit dem Menschen; Reden, Aufsätze, Essays (pp. 165-175). Rowohlt.

Salge, H. (2018). Die Idealisierung der Unschuld [The Idealization of Innocence]. Forum Psychoanal, 35, 19-35. https://doi.org/10.1007/s00451-018-0308-0

Schäfer, D., Möhring, J. V., \& Brosig B. (2020). Hilfen zwischen Schule und Beruf. Eine Evaluation der Bewältigung psychischer Problemlagen. Forum Sozialarbeit+Gesundheit, 4, 25-28.

Schnoor, H. (2011). Einführung. In Idem (Ed.), Psychodynamische Beratung: Ein Anwendungsgebiet der Psychoanalyse (pp. 7-18). Vandenhoeck \& Ruprecht. https://doi.org/10.13109/9783666401701.7

Seiffge-Krenke, I. (2020). Emerging Adulthood: Psychoanalytische Konzepte und empirische Befunde $\mathrm{zu}$ einer neuen Entwicklungsphase [Emerging Adulthood: Psychoanalytic Concepts and Empirical Findings on a New Developmental Phase]. Journal of Childhood and Adolescence Research, 15, 370-384.

Seiffge-Krenke, I., \& Beyers W (2016). Hatte Erikson doch recht? [Was Erikson Right after All?]. Psychotherapeut, 61, 16-21. https://doi.org/10.1007/s00278-015-0078-8

Sevecke, K., \& Resch, F. (2018). Identität-Eine Illusion? Selbstentwicklung in der Adoleszenz [Identity-An Illusion? Self Development in Adolescence]. Praxis der Kinderpsychologie und Kinderpsychiatrie, 67, 611-613. https://doi.org/10.13109/prkk.2018.67.7.611

Silva, J. M. (2013). Coming up Short. Working Class Adulthood in an Age of Uncertainty. Oxford University Press. https://doi.org/10.1093/acprof:oso/9780199931460.001.0001

Solga, H., \& Menze, L. (2013). Der Zugang zur Ausbildung: Wie integrationsfähig ist das deutsche Berufsbildungssystem? WSI-Mitteilungen, 66, 5-14.

Wollenhaupt, J. (2018). Die Entfremdung des Subjekts. Zur kritischen Theorie des Subjekts nach Pierre Bourdieu und Alfred Lorenzer. Transcript Verlag. https://doi.org/10.1515/9783839445525-005

Zahradnik, F. (2018). Schamangst und Sanktionierung: Affektive Verstrickungen junger Arbeitsloser in die Widersprüche der Grundsicherung. In S. Betzelt, \& I. Bode (Eds.), Angst im neuen Wohlfahrtsstaat: Kritische Blicke auf ein diffuses Phänomen (pp. 275-294). Nomos.

Zwiebel, R. (1984). Zur Dynamik des Gegenübertragungstraums [The Dynamics of the Countertransference Dream]. Psyche-Z. Psychoanal, 38, 193-213. 